\title{
Cornuvesica: A little known mycophilic genus with a unique biology and unexpected new species
}

\author{
S. Marincowitz ${ }^{a}$, T.A. Duong ${ }^{a, b}$, Z.W. de Beer ${ }^{a, c}$, M.J. Wingfield ${ }^{a}$ \\ ${ }^{a}$ Forestry and Agricultural Biotechnology Institute (FABI), University of Pretoria, Private Bag X20, Hatfield, \\ Pretoria 0028, Republic of South Africa. \\ ${ }^{b}$ Department of Genetics, University of Pretoria, Private Bag X20, Hatfield, Pretoria 0028, Republic of South \\ Africa. \\ 'Department of Microbiology and Plant Pathology, University of Pretoria, Private Bag X20, Hatfield, Pretoria \\ 0028, Republic of South Africa. \\ * Corresponding author. Tel. +27 214203937; fax +27 214203960. E-mail address: \\ seonju.marincowitz@fabi.up.ac.za
}

ABSTRACT: Little is known about the biology of the monotypic genus Cornuvesica (Microascales), apart from that isolates are notoriously difficult to culture on artificial media. A recent collection of material resembling this genus from freshly made wounds on Gmelina arborea in Indonesia, provided an opportunity to reconsider all available material of Cornuvesica falcata, type species of the genus. In addition to morphological comparisons, multigene phylogenetic analyses were made using sequences of the SSU, ITS, LSU and TEF1 a genes. Our results showed that the holotype of Cor. falcata from pine in Canada differed from all other material previously considered to represent this species and also from the new Indonesian collections. The collections considered represented three additional species that we describe here as new. Three New Zealand isolates and an isolate from UK were respectively described as Cor. acuminata and Cor. crypta, while the Indonesian isolates were described as Cor. magnispora. Phylogenies based on the SSU and LSU data sets showed that Cornuvesica spp. do not belong in the Ceratocystidaceae as previously suggested, but represent a distinct lineage in the Microascales that has yet to be named. Results showed that culture filtrates from other fungi or ferric chloride markedly stimulated the growth of Cor. magnispora.

KEYWORDS: Microascales; Culture enrichment; Commensal symbiosis; Ferric chloride Insect_associated fungi; Ceratocystidaceae

\section{INTRODUCTION}

The unusual and poorly known genus Cornuvesica includes a single ophiostomatoid fungus (Wingfield et al. 1993; Seifert et al. 2013) that has morphological features such as shortbeaked, minute ascomata with 2-celled falcate ascospores and two distinct thielaviopsis-like asexual states. These characteristics, unusual for the ophiostomatoid fungi, have resulted in 
Cornuvesica being poorly suited for inclusion in treatments of other ophiostomatoid genera broadly placed in the Ceratocystidaceae (Microascales) and the Ophiostomatales (Upadhyay 1981; Hausner et al. 1993; Wingfield 1993).

The type species, Cornuvesica falcata, was initially placed in Ceratocystis (Wright and Cain 1961), due to its similarity to Ceratocystis minuta (now Ceratocystiopsis minuta). It was later transferred to Ceratocystiopsis (Cop.) together with other ophiostomatoid species with falcate ascospores (Upadhyay 1981). Hausner et al. (1993) reduced Ceratocystiopsis to synonymy with Ophiostoma based on phylogenetic analyses of partial rDNA sequences. They, however, excluded some species, including Cop. falcata, due to its distant phylogenetic relatedness to Ophiostoma and unique morphological features. Viljoen et al. (2000) settled the generic placement of Cop. falcata by introducing a new, monotypic genus, Cornuvesica, to accommodate this species. Hausner and Reid (2004) showed, based on SSU sequences, that the genus represents a monophyletic lineage in the Microascales, sister to Ceratocystis. Cornuvesica was assigned to the Ceratocystidaceae together with Ceratocystis, Thielaviopsis and Ambrosiella (Réblovà et al. 2011; De Beer et al. 2013), genera that have most recently been revised by De Beer et al. (2014).

The biology of Cornuvesica falcata remains an enigma. The species was first isolated and described from decaying pine wood in Canada (Wright and Cain 1961). The fungus has also been reported from Britain where it was isolated from the stumps of fallen birch, beech and oak trees (Rayner and Hudson 1977), and New Zealand, where it was isolated from the galleries of bark beetles infesting larch and pine (Hutchison and Reid 1988). Although Cornuvesica is closely related to Ceratocystis, Graphium and Knoxdaviesia (De Beer et al. 2013), genera known for their association with arthropod vectors, a strong association between Cornuvesica and arthropods has not been confirmed. The only suggestion that such an association might exist, is that the fungus has been found in bark beetle galleries (Hutchison and Reid 1988), but for the present such evidence remains circumstantial.

Cornuvesica falcata grows poorly in artificial media. Wright and Cain (1961) failed to grow the fungus in culture. Rayner and Hudson (1977) and Hutchison and Reid (1988) obtained the fungus in culture, but growth was extremely slow (less than 1-1.6 mm per day). They, however, noticed that the presence of other fungi on culture plates stimulated growth. 
Rayner and Hudson (1977) reported an improvement of mycelial growth and ascomatal production when Cor. falcata grew on plates contaminated with other fungi such as Acremonium butyri or Trichoderma spp. The source of this stimulation remained unknown (Rayner and Hudson 1977). Hutchison and Reid (1988) noted that Cor. falcata in bark beetle galleries always occurred together with Gliocladium roseum. They prepared the media with culture extracts of $G$. roseum on which Cor. falcata grew and observed greater numbers of ascomata and larger conidia. Kawchuk et al. (1993) later investigated the stimulatory agent produced by $G$. roseum. It was a small hydrophilic compound with a weight of $1 \mathrm{kDa}$ and tolerant in autoclaving, but its function was not considered (Kawchuk et al. 1993). Most recently, Hausner et al. (2003) argued that the stimulating agent might not be 'solely of fungal origin' after they observed greater numbers of ascomata and increased mycelial growth of the New Zealand isolates on three different artificial media.

Not directly related to Cornuvesica but relevant to the present study, Thanh et al. (2002), when describing a new yeast species, made the discovery that Debaryomyces mycophilus required the presence of other commonly occurring fungi for its survival in culture. These fungi included a Fusicoccum sp. and a Graphium sp., the culture filtrates of which improved the growth of the yeast. The growth promoting factors were identified as siderophores (Thanh et al. 2002). These authors further discovered that supplementing $300 \mu \mathrm{M}$ ferric chloride $\left(\mathrm{FeCl}_{3}\right)$ to the culture media produced the same effect as the presence of the Fusicoccum and Graphium species, confirming the role of these two fungi as donors of siderophores (Thanh et al. 2002).

The present study emerged from the recent discovery of a fungus resembling Cornuvesica falcata on wounds freshly made on the stems of Gmelina aborea trees in Kalimantan, Indonesia. The aim of the investigation was to identify this species, but also to reconsider the taxonomy of Cor. falcata based on morphology and DNA sequence comparisons by including all available material of this fungus from international collections. Since the Indonesian fungi grew very poorly in culture, we also explored techniques to enhance growth in culture, and at the same time considered the possible reasons for such behaviour in an attempt to better understand the biology of the genus. 


\section{MATERIALS AND METHODS}

Isolates

A block of bark (approx. $10 \mathrm{~cm}^{2}$ ) was removed from the trunks of Gmelina arborea trees growing in Northern Kalimantan, Indonesia and close to the town of Berau, and a small wedge of wood was removed to expose the xylem vessels. Six weeks after wounding, pieces of wood were removed from the wounds, placed in plastic bags and transported to the laboratory for study. Small ascomata were observed on the wood samples placed under a dissection microscope and fine tendrils of ascospores were found emerging from them. These ascospore tendrils were lifted from the ascomata using a sterile needle and transferred to malt extract agar (MEA: $2 \%$ Biolab malt extract, 2 \% Difco agar) supplemented with streptomycin $(400 \mathrm{mg} / \mathrm{L})$. This resulted in cultures that grew extremely slowly.

Table 1. Isolates and herbarium specimens previously treated as Cornuvesica falcata that were included in the present study.

\begin{tabular}{|c|c|c|c|c|}
\hline $\begin{array}{l}\text { Voucher } \\
\text { specimen and } \\
\text { cultures }\end{array}$ & Host plant & Substrate & Origin of locality & References \\
\hline $\begin{array}{l}{ }^{\mathrm{a}} \text { TRTC } 33037 \\
\text { (holotype) }\end{array}$ & Pinus strobus & Sapwood & $\begin{array}{l}\text { Canada, Ontario, York Co., NW of } \\
\text { Nobleton }\end{array}$ & Wright and Cain 1961 \\
\hline $\begin{array}{l}{ }^{\mathrm{b}} \mathrm{Herb} . \mathrm{IMI} \\
200338\end{array}$ & Betula pendula & $\begin{array}{l}\text { Sections cut from } \\
\text { stumps }\end{array}$ & $\begin{array}{l}\text { UK, England, Suffolk, King's Forest, coll. } \\
\text { March 1975, by ADM Rayner }\end{array}$ & $\begin{array}{l}\text { Rayner and Hudson } \\
1977\end{array}$ \\
\hline${ }^{\mathrm{C}}$ ATCC 36538 & Betula sp. & Unspecified & UK, England (deposited by HJ Hudson) & Viljoen et al. 2000 \\
\hline- & $\begin{array}{l}\text { B. pendula, Fagus } \\
\text { sylvatica, } \\
\text { Quercus robur }\end{array}$ & $\begin{array}{l}\text { Sections cut from } \\
\text { stumps }\end{array}$ & UK, England, Norfolk, near Thetford & $\begin{array}{l}\text { Rayner and Hudson } \\
1977\end{array}$ \\
\hline $\begin{array}{l}\text { dUAMH } 9701 \\
\text { (=UM 487) }\end{array}$ & Larix sp. & $\begin{array}{l}\text { Beetle galleries in the } \\
\text { inner bark or outer } \\
\text { sapwood }\end{array}$ & $\begin{array}{l}\text { New Zealand, Taupo, Kaingaroa State } \\
\text { forest, Waiotapu, compartment } 5 \\
(1982 / 05 / 08)\end{array}$ & $\begin{array}{l}\text { Hutchison and Reid } \\
\text { 1988, Hausner et al. } \\
2003\end{array}$ \\
\hline- & Pinus radiata & $\begin{array}{l}\text { Beetle galleries in the } \\
\text { inner bark or outer } \\
\text { sapwood }\end{array}$ & $\begin{array}{l}\text { New Zealand, Auckland, Woodhill State } \\
\text { Forest, compartment } 37 \text { (1982/05/14); } \\
\text { Coromandel, Whangapoua State Forest, } \\
\text { off road } 41 \text { (1982/05/19) }\end{array}$ & $\begin{array}{l}\text { Hutchison and Reid } \\
1988\end{array}$ \\
\hline $\begin{array}{l}\text { 'UAMH } 9702 \\
\text { (=UM } 792= \\
\text { WIN(M) 792); } \\
\text { UAMH 9703 } \\
\text { (=UM 793) }\end{array}$ & Pinus radiata & Unspecified & $\begin{array}{l}\text { New Zealand, Taupo, Kaingaroa State } \\
\text { Forest, compartment } 1212\end{array}$ & $\begin{array}{l}\text { Hausner et al. 1993, } \\
\text { 2003, Hausner and Reid } \\
\text { 2004, Réblovà et al. } \\
2011\end{array}$ \\
\hline \multicolumn{5}{|c|}{ a. Royal Ontario Museum Mycology Herbarium (TRTC) } \\
\hline \multicolumn{5}{|c|}{ b. CABI Bioscience UK Centre Herbarium (Herb. IMI) } \\
\hline \multicolumn{5}{|c|}{ c. American Type Culture Collection (ATCC) } \\
\hline d. the Univ & of Alberta Mic & ungus Collectior & (IIAMH) & \\
\hline
\end{tabular}

All the isolates generated in this study were deposited in the culture collection (CMW) of the Forestry and Agricultural Biotechnology Institute, University of Pretoria, Pretoria, South 
Africa and the ex-type cultures in the Centraalbureau voor Schimmelcultures (CBS), Utrecht, the Netherlands. Dried cultures were deposited with the National Collection of Fungi in South Africa (PREM). For comparative purposes, the only four existing cultures of Cor. falcata were obtained from international culture collections (Table 1). In addition, herbarium specimens for all collections of this fungus were sourced for detailed examination.

\section{Growth in culture and cultural characteristics}

Isolates were grown on three different media that have previously been shown to enhance the growth of Cornuvesica falcata in culture. These included a medium amended with a mycelial extract of Gliocladium roseum (Kawchuk et al. 1993), that was obtained from the CMW collection, a composite medium (CM) described by Hausner et al. (1993), which included $17 \mathrm{~g}$ cornmeal agar, $10 \mathrm{~g}$ malt extract, $1 \mathrm{~g}$ yeast extract and $10 \mathrm{~g}$ agar in $1 \mathrm{~L}$ water and a medium used by Viljoen et al. (2000), which included $10 \mathrm{~g}$ malt extract, $10 \mathrm{~g}$ yeast extract, $5 \mathrm{~g}$ tryptone, $2 \mathrm{~g}$ yeast carbon base and $20 \mathrm{~g}$ agar in $1 \mathrm{~L}$ water. In addition, an MEA medium amended with $300 \mu \mathrm{M} \mathrm{FeCl}_{3}$ (Thanh et al. 2002) was used, in an attempt to stimulate the growth of cultures.

To study culture characteristics, growth rates and the effect of an iron supplement, two culture media were used. The New Zealand and British isolates were plated on CM and the Indonesian isolates on MEA. To assess the effect of an iron supplement, the medium was amended with $300 \mu \mathrm{M} \mathrm{FeCl}_{3}$ and a control was without an iron supplement. The cultures were prepared by placing a $5 \mathrm{~mm}$ diam agar plug bearing actively growing mycelium from a 4-week-old culture at the centre of a $90 \mathrm{~mm}$ Petri dish. The cultures were grown in the dark for $21 \mathrm{~d}$ at temperatures ranging from $15{ }^{\circ} \mathrm{C}$ to $35^{\circ} \mathrm{C}$ at $5{ }^{\circ} \mathrm{C}$ intervals with five replicates for each test isolate at each temperature. Two diameter measurements, perpendicular to each other, were made for each culture and the average of the diameters was computed.

Three Indonesian isolates (CMW 37280, 37282, 37284) were tested for their sensitivity to the antibiotic cycloheximide at $0.05 \%(500 \mathrm{mg} / \mathrm{L})$. The cultures were prepared by placing a 5 $\mathrm{mm}$ diam agar plug containing actively growing mycelium at the centre of a $90 \mathrm{~mm}$ Petri dish. The cultures, including five replicate plates for each isolate, were placed in the dark at 
temperatures ranging from $15^{\circ} \mathrm{C}$ to $35^{\circ} \mathrm{C}$ at $5{ }^{\circ} \mathrm{C}$ intervals for $21 \mathrm{~d}$. The sensitivity to cycloheximide was described as percentage inhibition of colony areas $\left(\pi r^{2}\right)$ on media containing cycloheximide versus the controls (Hausner et al. 1993).

Effect of extracellular metabolites on the growth of the Indonesian isolate

Four fungal species were chosen for the extraction of extracellular metabolites: Fusicoccum sp. (CMW 325) and Graphium sp. (CMW 729) that had previously been shown to produce an extracellular metabolite facilitating iron uptake in a yeast (Thanh et al. 2002), Ceratocystis sp. (CMW 36613) and a hypocrealean fungus (CMW 37146) that was found growing together with the Indonesian Cornuvesica sp. on the wood from which this fungus was isolated.

Four $500 \mathrm{~mL}$ flasks containing $250 \mathrm{~mL}$ yeast-malt broth (YM broth: $5 \mathrm{~g}$ malt extract, $0.5 \mathrm{~g}$ yeast extract, $250 \mathrm{~mL}$ water) were inoculated with mycelium of each of the four test fungi and placed in a shaker at $150 \mathrm{rpm}$ near UV light at $21^{\circ} \mathrm{C}$ for $5 \mathrm{~d}$. Culture fitrates were collected from the flasks using a vacuum filter. The $50 \mathrm{ml}$ filtrates were then added to 450 $\mathrm{ml}$ yeast-malt extract agar (YMA: $2 \%$ malt extract, $0.2 \%$ yeast extract, $2 \%$ agar). The culture filtrate medium was autoclaved at $121^{\circ} \mathrm{C}$ for $20 \mathrm{~min}$ and $30 \mathrm{~mL}$ was then dispensed into $90 \mathrm{~mm}$ Petri dishes.

Six different sets of YMA were prepared: one without culture filtrate used as a control, one with $300 \mu \mathrm{M} \mathrm{FeCl}_{3}$ and four representing each of the different culture filtrates. Five $\mathrm{mm}$ diam plugs containing mycelium of the Indonesian Cornuvesica sp. (CMW 37282) were placed at the centres of $90 \mathrm{~mm}$ Petri dishes. Five replicate plates for each of the six test media (control, iron and four culture filtrates) were incubated at $25^{\circ} \mathrm{C}$ and $30{ }^{\circ} \mathrm{C}$ in the dark for $7 \mathrm{~d}$. These two temperatures were shown to support the best growth of the isolate in the growth study. The growth was assessed by measuring the average of the colony diameters, which included two diameter measurements perpendicular to each other for each plate. 


\section{Microscopy and morphology}

A study of the morphology of isolates was undertaken using a Zeiss Axioskop2 Plus compound microscope or a Zeiss Discovery V12 dissection microscope. Images were captured by an AxioCam ICc 3 camera and drawings were prepared using a drawing tube. All the microscopic features were studied on glass slides with specimens mounted in $85 \%$ lactic acid other than for those of the herbarium specimens that were examined in $10 \% \mathrm{KOH}$. Measurements of characteristic morphological features were made using the Axiovision 4.8 software. Twenty-five to fifty measurements were made for each structure depending on their availability. Sizes of structures are presented with a $95 \%$ confidence level.

\section{DNA preparation, $P C R$ and sequencing}

Fungal isolates were grown in $\mathrm{YM}$ broth supplemented with $300 \mu \mathrm{M} \mathrm{FeCl}$. After one to two weeks of incubation at $25^{\circ} \mathrm{C}$ on a rotary shaker set at $150 \mathrm{rpm}$, fungal mycelium was harvested by centrifugation. DNA samples were prepared from the fresh fungal mycelium using PrepMan Ultra reagent (Applied Biosystems, Foster City, California) following the method used by Duong et al. (2012). DNA samples were kept at $-20^{\circ} \mathrm{C}$ for further analyses.

Four gene regions were amplified, sequenced and used in phylogenetic analyses. These included the large subunit (LSU), the small subunit (SSU) and the internal transcribed spacers 1 and 2 (ITS1-ITS2) of the ribosomal DNA, and partial sequence of the translation elongation factor-1 alpha (TEF-1 $\alpha$ ) gene. The primers for PCR amplification and sequencing were LROR and LR5 (Vilgalys and Hester 1990) for LSU, NS1 and NS4 (White et al. 1990) for SSU, ITS1 and ITS4 (White et al. 1990) for ITS1-ITS2 and EF2F (5'-GGTCAYYTGATCTACCAGTG3'; designed in this study) and EF2R (Jacobs et al. 2004) for TEF-1 $\alpha$. The protocols for PCR and sequencing were the same as those described by Duong et al. (2012).

\section{Phylogenetic analyses}

To investigate the taxonomic relationship between Cornuvesica and other families in the Microascales, SSU and LSU datasets were compiled from SSU and LSU sequences of Cornuvesica and other representative species residing in different families and orders in the Hypocreomycetidae. Representative species in the Xylariales and Lulworthiales were used as 
outgroups in the analyses of SSU and LSU datasets. The ITS and EF-1 $\alpha$ datasets were compiled from ITS and EF-1 $\alpha$ sequences of all Cornuvesica isolates included in this study (Table 2). Knoxdaviesia proteae, Ceratocystis fimbriata and Huntiella (Ceratocystis) moniliformis were used as outgroup taxa in the analyses of ITS dataset. Due to the unavailability of EF-1 $\alpha$ sequences for $K$. proteae, only $C$. fimbriata and $H$. moniliformis were used as outgroup taxa in the analyses of the EF-1 $\alpha$ dataset.

Table 2. Isolates sequenced in this study including GenBank accession numbers.

\begin{tabular}{|c|c|c|c|c|c|c|c|}
\hline \multirow[t]{2}{*}{ Species } & \multirow[t]{2}{*}{ Isolate No. } & \multirow{2}{*}{$\begin{array}{l}\text { Geographical } \\
\text { Origin }\end{array}$} & \multirow[t]{2}{*}{ Host } & \multicolumn{4}{|c|}{ GenBank accession numbers } \\
\hline & & & & LSU & SSU & ITS & EF \\
\hline Cor. crypta & ${ }^{\mathrm{ET}}$ ATCC $36538={ }^{\mathrm{a}} \mathrm{CMW} 37652$ & Britain & Betula sp. & KP888984 & KP888956 & KP888975 & KP888968 \\
\hline Cor. acuminata & UAMH 9701 = CMW 37653 & New Zealand & Larix sp. & & & KP888974 & KP888969 \\
\hline Cor. acuminata & 'UAMH 9702 = CMW 37654 & New Zealand & Pinus radiata & KP888987 & KP888959 & KP888972 & KP888970 \\
\hline Cor. acuminata & UAMH 9703 = CMW 37655 & New Zealand & P. radiata & & & KP888973 & KP888971 \\
\hline Cor. magnispora & ${ }^{\mathrm{b}} \mathrm{CBS} 134698$ = CMW 37280 & Indonesia & Gmelina arborea & KP888985 & KP888957 & KP888976 & KP888964 \\
\hline Cor. magnispora & CMW 37281 & Indonesia & G. arborea & & & KP888977 & KP888960 \\
\hline Cor. magnispora & ${ }^{\top}$ CBS $134697=$ CMW 37282 & Indonesia & G. arborea & KP888986 & KP888958 & KP888978 & KP888962 \\
\hline Cor. magnispora & CMW 37283 & Indonesia & G. arborea & & & KP888981 & KP888963 \\
\hline Cor. magnispora & CMW 37284 & Indonesia & G. arborea & & & KP888982 & KP888967 \\
\hline Cor. magnispora & CMW 37285 & Indonesia & G. arborea & & & KP888980 & KP888961 \\
\hline Cor. magnispora & CMW 37286 & Indonesia & G. arborea & & & KP888983 & KP888966 \\
\hline Cor. magnispora & CBS $134699=$ CMW 37287 & Indonesia & G. arborea & & & KP888979 & KP888965 \\
\hline
\end{tabular}

a. Culture collection of the Forestry and Agricultural Biotechnology Institute (FABI), University of Pretoria, South Africa (CMW)

b. Centraalbureau voor Schimmelcultures, Utrecht, the Netherlands (CBS)

ET: ex-epitype, T: ex-holotype

Each dataset was analysed separately. Alignments were done using an online version of MAFFT 7 (Katoh and Standley 2013). In the case of the ITS and EF-1 $\alpha$ datasets, optimal substitution models were determined using jModelTest 2 (Darriba et al. 2012). Maximum parsimony (MP) analyses were performed in MEGA 6 (Tamura et al. 2013) where treebisection-reconnection branch-swapping algorithm was used; bootstrap replications were set at 1000 and gaps and missing data were included. Maximum likelihood (ML) analyses of ITS and EF-1 $\alpha$ datasets were performed in MEGA 6 (Tamura et al. 2013) where a subtreepruning-regrafting heuristic search level 5 was used; the bootstrap replication was set at 1000 and gaps and missing data were included. ML analyses of SSU and LSU datasets were performed using raxmIGUI (Silvestro and Michalak 2012) with the GTR+G+I model selected. Ten parallel runs, each with four threads and 1000 bootstrap replicates, were conducted. Bayesian inference (BI) analyses were performed using MrBayes 3.2 (Ronquist et al. 2012) 
applying the $\mathrm{GRT}+\mathrm{G}+\mathrm{I}$ model. Ten parallel runs, each with 2.000 .000 generations, were conducted. Trees were sampled at every $100^{\text {th }}$ generation. Trees sampled in the burn-in phase ( $25 \%$ of the trees sampled) were discarded and posterior probabilities were calculated from the remaining trees.

\section{RESULTS}

Isolates

Twelve Cornuvesica isolates were considered in this study. These included a British isolate purchased from the American type culture collection (ATCC, U.S.A.), three New Zealand isolates purchased from the University of Alberta Microfungus Collection and Herbarium (UAMH, Canada) and eight isolates collected from the wounded G. arborea trees in Northern Kalimantan (Table 2). In addition, herbarium specimens of the holotype of Cor. falcata were obtained from the Royal Ontario Museum Mycology Herbarium (TRTC, Canada) and a British specimen of Cor. falcata described by Rayner and Hudson (1977) was obtained from CABI Bioscience UK Centre herbarium (Herb. IMI, U.K.) (Table 1).

\section{Growth in culture and cultural characteristics}

Of the four culture media screened for the growth of Cor. falcata, CM showed the best result for the British and New Zealand isolates and MEA provided the best substrate for growth of the Indonesian isolates. The growth study was thus performed on these two media. Neither the British nor the New Zealand isolates grew at temperatures above $30^{\circ} \mathrm{C}$ and they displayed extremely slow growth at other temperatures (7-20 mm diam in $21 \mathrm{~d}$ ). The Indonesian isolates grew slowly at all temperatures (7-27 mm diam in $21 \mathrm{~d})$. The iron supplement showed a positive effect on the Indonesian isolates but almost no effect on the British and New Zealand isolates. The sensitivity of the Indonesian isolates to cycloheximide was assessed between $20^{\circ} \mathrm{C}$ and $30^{\circ} \mathrm{C}$ where vigorous growth occurred. All three isolates showed sensitivity. The details of growth characteristics for each isolate are provided in the taxonomy section. 


\section{Effect of extracellular metabolites on the growth of an Indonesian isolate}

Culture filtrates of all four test fungi produced some level of stimulation to the growth of the Indonesian Cornuvesica sp. (Fig. 1). This growth stimulation was greater at $30^{\circ} \mathrm{C}$ than at $25^{\circ} \mathrm{C}$. The Fusicoccum sp. (CMW 325) culture extract resulted in colonies of Cornuvesica sp. growing 5-6 times $\left(63 \mathrm{~mm}\right.$ diam at $25^{\circ} \mathrm{C}, 75 \mathrm{~mm}$ at $30^{\circ} \mathrm{C}$ ) larger than the control $(12 \mathrm{~mm})$. The Ceratocystis sp. (CMW 36613) extract resulted in 4-5 times larger $\left(51 \mathrm{~mm}\right.$ at $25^{\circ} \mathrm{C}, 62$ $\mathrm{mm}$ at $30^{\circ} \mathrm{C}$ ) colonies, the Graphium sp. (CMW 729) in 3-4 times larger $\left(40 \mathrm{~mm}\right.$ at $25^{\circ} \mathrm{C}, 50$ $\mathrm{mm}$ at $30^{\circ} \mathrm{C}$ ) colonies and the hypocrealean fungus (CMW 37146) in 3 times larger (38 mm at $25^{\circ} \mathrm{C}, 40 \mathrm{~mm}$ at $30^{\circ} \mathrm{C}$ ) colonies. All the cultures grown on the medium supplemented with culture filtrates produced sexual states in $14 \mathrm{~d}$. Amongst these, the medium including the Fusicoccum sp. (CMW 325) extract gave rise to sexual structures first.
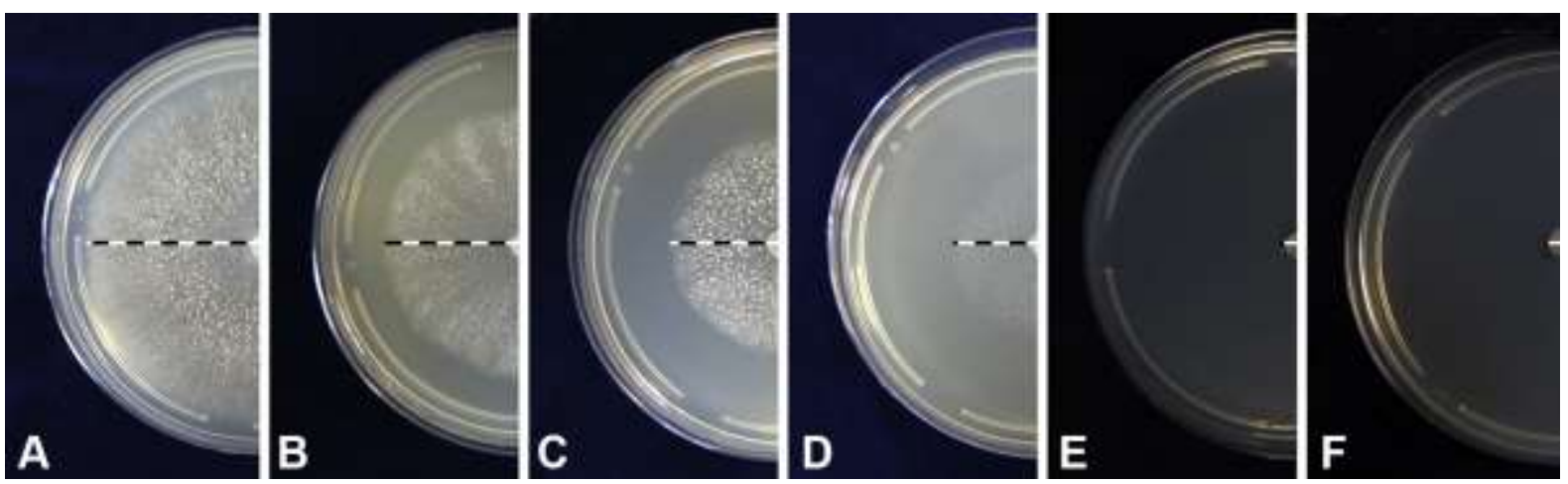

Fig. 1. Growth of Cornuvesica magnispora on the YMA media amended with culture filtrates, ferric chloride or nothing in the dark for $7 \mathrm{~d}$ at $30^{\circ} \mathrm{C}$. From $A$ to $D$ each plate represents different culture filtrate of the following fungi. a. Fusicoccum sp. (CMW 325). b. Ceratocystis sp. (CMW 36613). c. Graphium sp. (CMW 729). d. A hypocrealean fungus (CMW 37146). e. Supplemented with $300 \mu \mathrm{M} \mathrm{FeCl}_{3}$. f. With no supplement. Scale bars: a single unit white or black bar $=3.5 \mathrm{~mm}$.

\section{Phylogenetic analyses}

The SSU dataset consisted of 65 taxa and had 1014 characters including alignment gaps, of which 654 were constant and 261 were parsimony-informative. The LSU dataset consisted of 73 taxa and had 745 characters including alignment gaps, of which 336 were constant and 362 were parsimony-informative. The SSU sequence (GB: AY271797) generated from a New Zealand isolate of Cornuvesica (UAMH 9702) in Hausner and Reid (2004) did not match with SSU sequence generated from the same isolate in this study and that sequence was consequently not included in the analyses. The ITS dataset consisted of 640 characters, of 


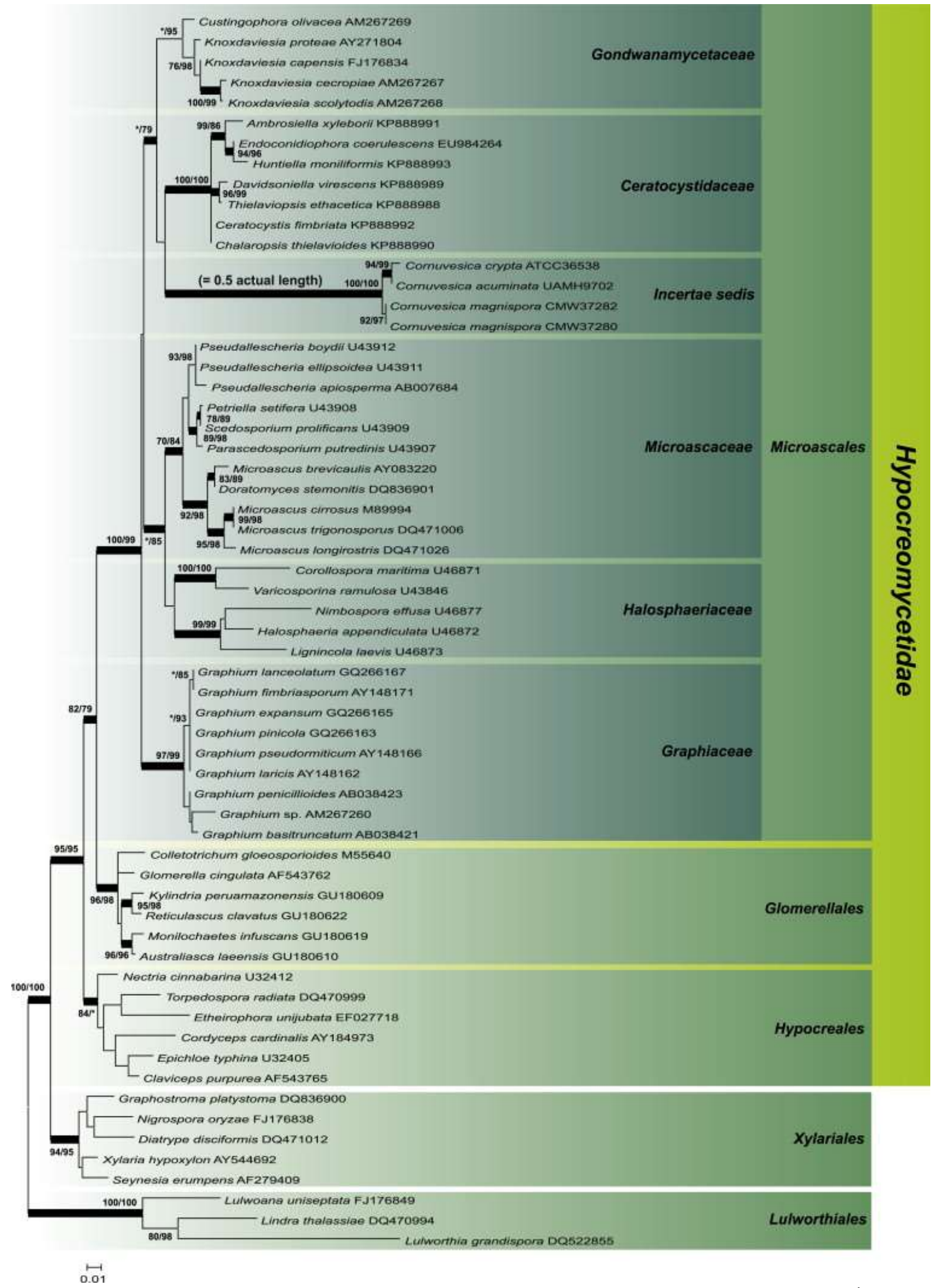

Fig. 2. Phylogenetic tree derived from $M L$ analyses of SSU dataset. Bootstrap supports ( $\geq 75 \%$ ) for $M L / M P$ are presented at nodes. Thick branches represent BI posterior probabilities $\geq 95 \%$. To aid with tree presentation, the branch length for the Cornuvesica clade has been shortened by half as indicated in the tree. 


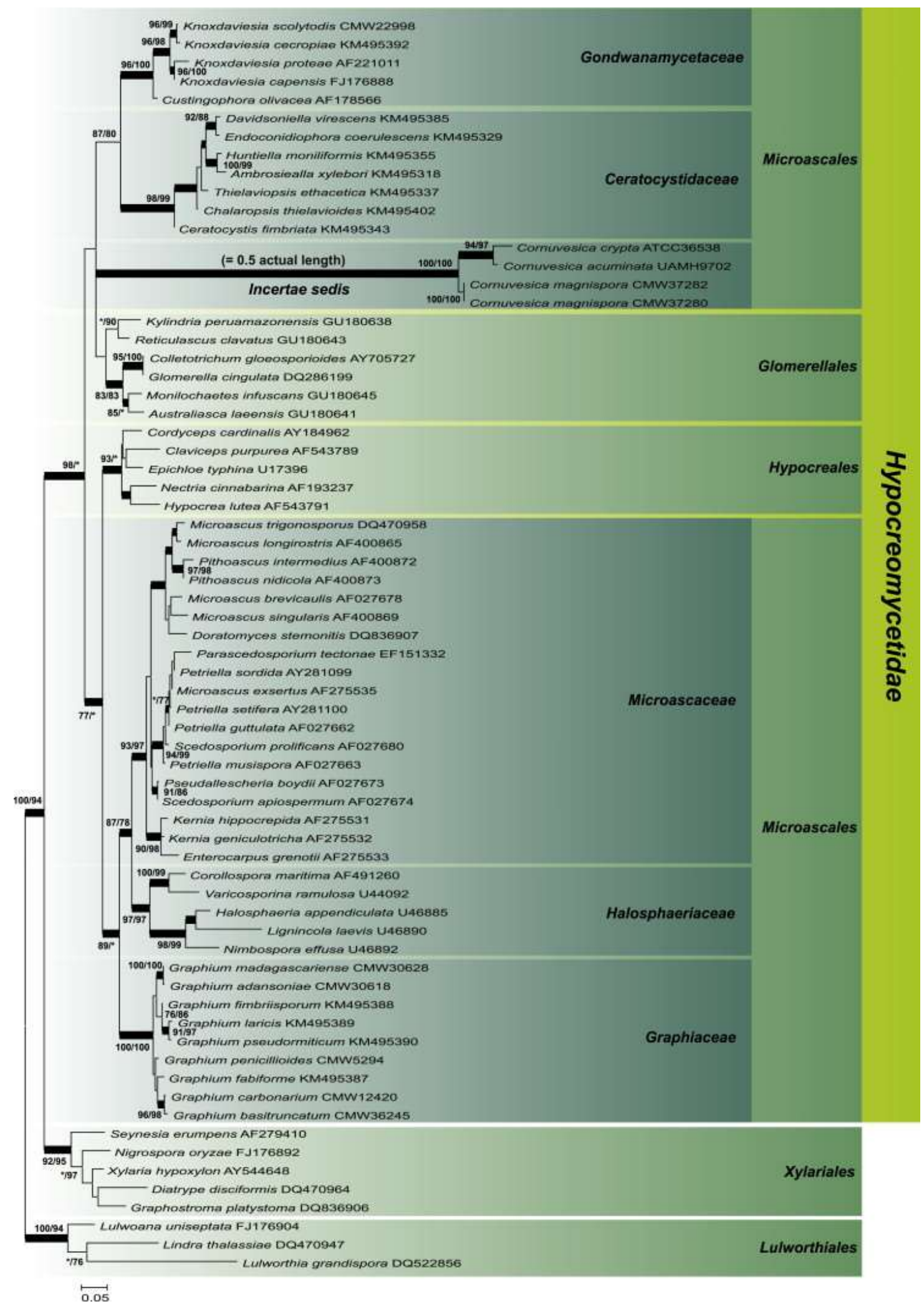

Fig. 3. Phylogenetic tree derived from $M L$ analyse of LSU dataset. Bootstrap supports ( $\geq 75 \%$ ) for $M L / M P$ are presented at nodes. Thick branches represent BI posterior probabilities $\geq 95 \%$. To aid with tree presentation, the branch length for the Cornuvesica clade has been shortened by half as indicated in the tree. 
which 330 characters were constant and 148 characters were parsimony-informative. The EF-1 $\alpha$ dataset had 921 characters, of which 683 characters were constant and 71 characters were parsimony-informative. As determined by jModelTest 2 , the GTR+I substitution model was used in the analyses of ITS and EF-1 $\alpha$. GTR+G were used in the analyses of SSU and LSU datasets.

Trees resulting from analyses of SSU and LSU differed in topologies. However, all the major lineages representing different families and orders could clearly be identified. In all the analyses of SSU and LSU datasets, isolates of Cornuvesica consistently formed a strongly supported monophyletic clade and were relatively closely related to species in the Ceratocystidaceae and Gondwanamycetaceae. In the analyses of SSU dataset, Cornuvesica species formed a monophyletic clade with members of the Ceratocystidaceae and Gondwanamycetaceae and resided in the Microascales. This relationship was, however, not clear in the LSU dataset. Phylogenetic trees resulting from ML analyses of the SSU and LSU datasets are presented in Fig. 2 and Fig. 3 respectively.

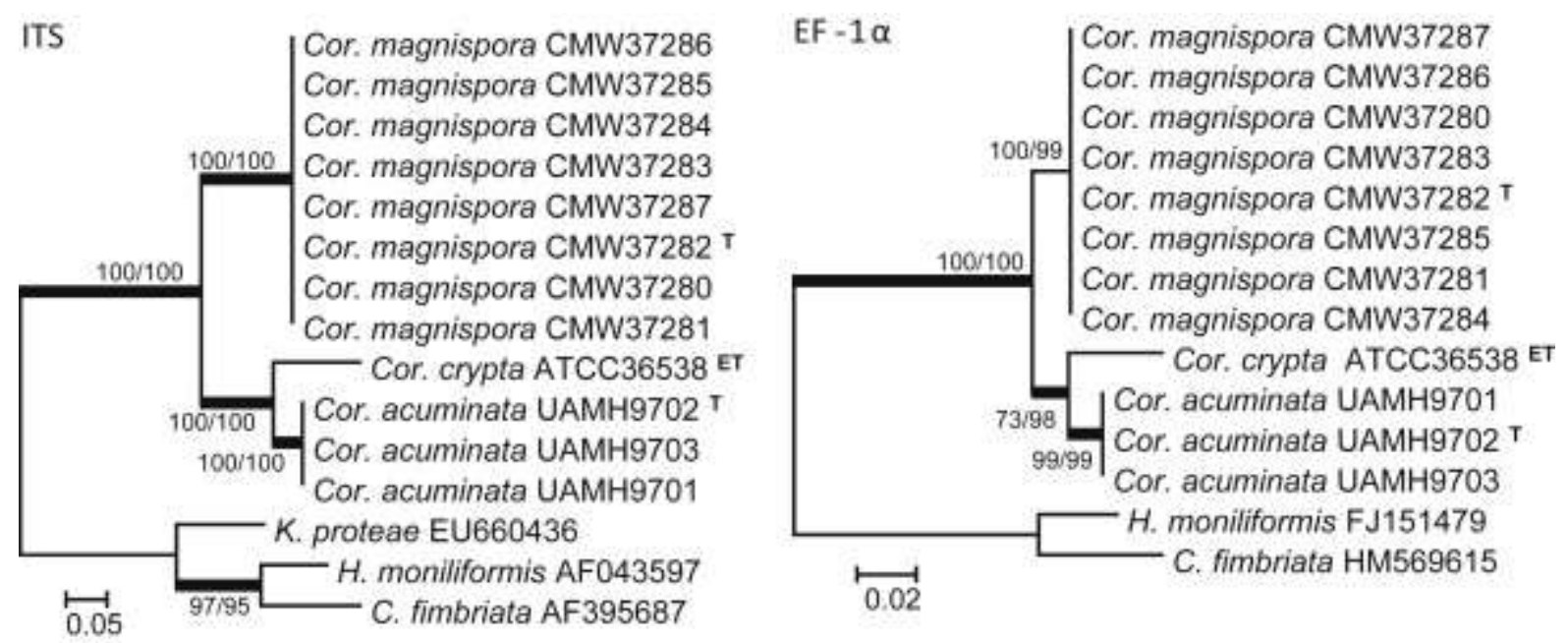

Fig. 4. Phylogenetic trees derived from ML analyses of ITS and EF-1 $\alpha$ datasets. Bootstrap supports ( $\geq 75 \%)$ for $\mathrm{ML} / \mathrm{MP}$ are presented at nodes. Thick branches represent BI posterior probabilities $\geq 95 \%$. ET: ex-epitype, T: ex-holotype.

Phylogenetic analyses of ITS and EF-1 $\alpha$ datasets resulted in trees with the same topology in all (MP, ML and $\mathrm{BI}$ ) of the analyses (Fig. 4). Isolates from Indonesia always grouped together forming a well-supported lineage. The three isolates from New Zealand previously known as Cop. falcata also formed a distinct, well-supported lineage, while the single isolate from Britain was distinct from the other two lineages in all trees. Although the data sets were 
small, the three lineages encompassing the Cornuvesica isolates considered in this study consistently grouped together with strong statistical support, distinguishing them from the Knoxdaviesia and Ceratocystis outgroup taxa.

\section{Taxonomy}

Phylogenetic analyses and morphological comparisons revealed a well-supported monophyletic lineage in the Microascales that included three distinct taxa, described here as new species, that are morphologically distinct from the type species, Cornuvesica falcata. Morphology and phylogenetic analyses confirmed that isolates previously treated as Cor. falcata from Britain (Rayner and Hudson 1977) and New Zealand (Hutchison and Reid 1988) as well as those collected in the present study from Indonesia, were all distinct from the holotype of Cor. falcata originally collected in Canada. Because the morphological descriptions of Cor. falcata subsequent to the original species description represented various different species as shown in the present study, a new description for Cor. falcata based only on the holotype specimen is provided. This was then compared and contrasted with the three new species recognised in this study.

Cornuvesica falcata (E.F. Wright \& Cain) C.D. Viljoen, M.J. Wingf. \& K. Jacobs, Mycol. Res. 104: 366. 2000. emend. Marinc., T.A. Duong, Z.W. De Beer, M.J. Wingf. Fig. 5a-c, 7e, f. Synonyms: Ceratocystis falcata E.F. Wright \& Cain, Can. J. Bot. 39: 1226. 1961 Ceratocystiopsis falcata (E.F. Wright \& Cain) H.P. Upadhyay, Monogr. Ceratocystis and Ceratocystiopsis, p. 125. 1981.

On a mounted microscope slide enclosed in the type specimen, Ascomata brown, beak darker than base, 60-90 $\mu \mathrm{m}$ diam. Ascospores hyaline, falcate, gradually attenuating towards both ends, with one end more attenuated, straight or slightly curved, 1-septate, septum indistinct, supra-median, $(22-) 25-27(-30) \times 1-2 \mu \mathrm{m}$ (avg. $26.1 \times 1.3 \mu \mathrm{m})$, thinwalled, smooth. No asexual structures observed.

Specimen examined: Canada: Ontario, York Co., NW of Nobleton, on the sapwood of Pinus strobus, 1 July 1957, R.F. Cain, TRTC 33037, holotype.

Notes - The holotype specimen included wood pieces and two microscope slides. Unfortunately no evidence of Cor. falcata could be found on the wood pieces but the 
Cornuvesica species_15

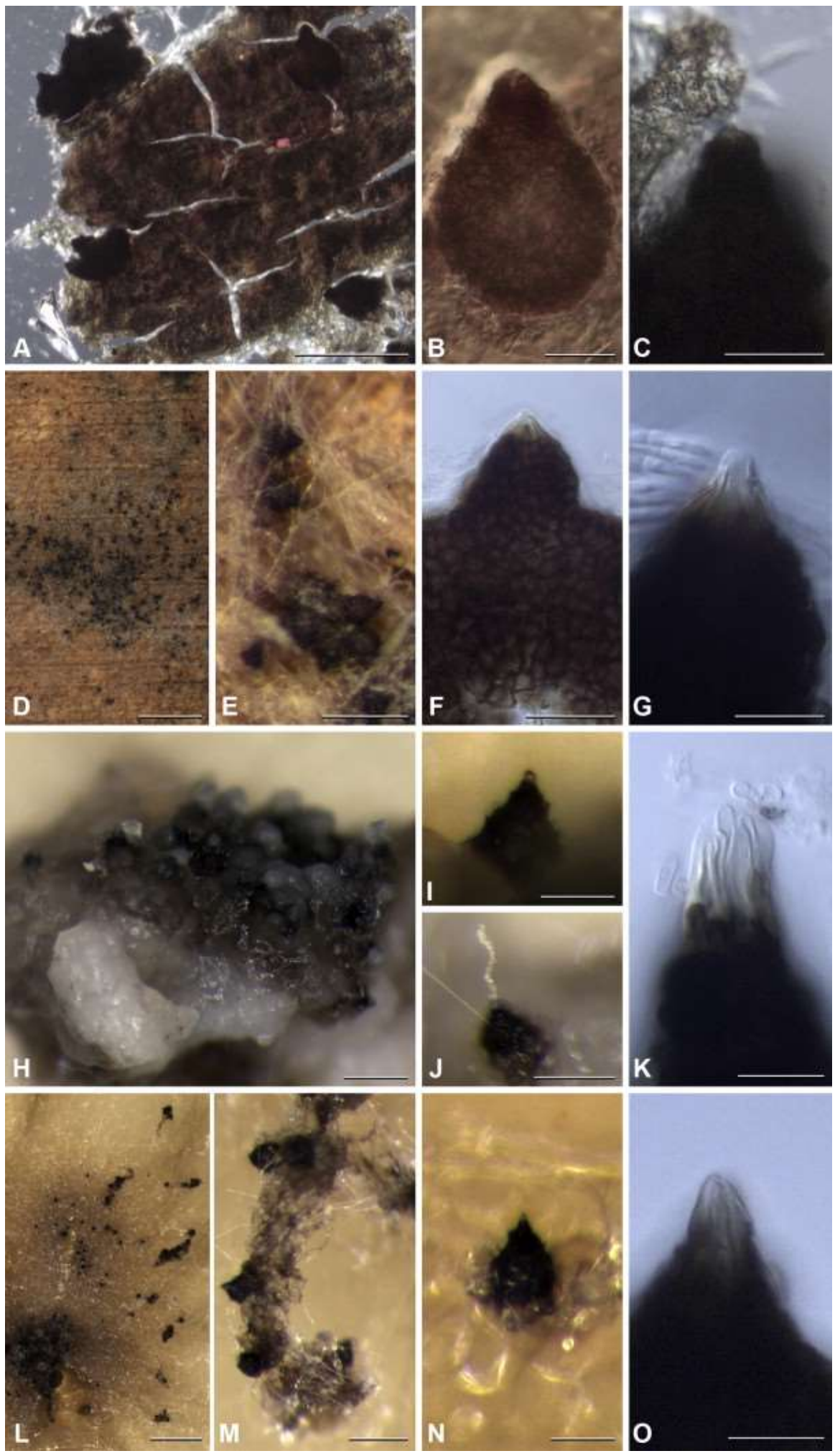

Fig. 5. Photographic images of ascomata. a-c. Cornuvesica falcata (TRTC 33037). d-g. Cor. crypta (Herb. IMI 200338). h-k. Cor. acuminata (UAMH 9702). I-o. Cor. magnispora (CBS $134697=$ CMW 37282). a, d, e.

Ascomata on the host substrate. $h, l, m$. Ascomata on the artificial media. b, f, i, $n$. A single ascoma. j. A single ascoma with a cirrhus. c, g, k, o. Convergent ostiolar hyphae. Scale bars: $d, i=2 \mathrm{~mm}, \mathrm{~h}=500 \mu \mathrm{m}, \mathrm{a}, \mathrm{e}, \mathrm{j}, \mathrm{m}=$ $250 \mu \mathrm{m}, \mathrm{l}, \mathrm{n}=100 \mu \mathrm{m}, \mathrm{b}, \mathrm{c}, \mathrm{f}=25 \mu \mathrm{m}, \mathrm{g}, \mathrm{k}, \mathrm{o}=10 \mu \mathrm{m}$. 
microscope slides were fairly well-preserved. On the one slide, ascomata on a wooden substrate and ascospores were clearly visible (Fig. 5a-c, 7e). Wright and Cain (1961) reported that they did not observe any asexual state on the specimen and also failed to grow the fungus in artificial media. The only possibility to confirm the phylogenetic position of this species would be to collect fresh material from the same host and origin, which could then be designated as an epitype.

Cornuvesica crypta Marinc., T.A. Duong, Z.W. De Beer, M.J. Wingf., sp. nov. - MycoBank MB 811610; Fig. 5d-g, 6a, d, e, 7a-d.

Etymology - name refers to the fact this species was obscured in having been treated as Cor. falcata.

On wood, Ascomata scattered or clustered in groups, superficial, embedded in loose mycelial mat on which asexual states are formed, sparsely covered with brown conidiophores, with conical opening distinctly recognizable, dark brown to blackish, 70-100 $\mu \mathrm{m}$ diam. Peridium firm, pseudoparenchymatous, textura epidermoidea to angularis. Ostiolar hyphae convergent, compactly adhered to each other, pale brown to hyaline. Asci evanescent. Ascospores hyaline, falcate, gradually attenuating towards both ends, with one end more attenuated and frequently curved like a hook, straight or slightly curved, 1septate, septum indistinct, supra-median, (21-)25-27(-31) × 1-2 $\mu \mathrm{m}$ (avg. $26 \times 1.4 \mu \mathrm{m})$, thin-walled, smooth. Asexual states thielaviopsis-like with two distinct ranges of conidial dimensions. Micro- and Macro-conidiophores micronematous, semi-macronematous, mostly unbranched, cylindrical, septated. Micro-conidiogenous cells phialidic, collarette indistinct, hyaline, discrete, mostly intercalary, cylindrical gradually tapering to the apex, straight or curved, (21-)28-32(-47) $\mu \mathrm{m}$ long, (3-)3.5-4(-5) $\mu \mathrm{m}$ wide near the base, $2-3 \mu \mathrm{m}$ wide near the apex. Macro-conidiogenous cells phialidic, collarette indistinct, pale brown to brown, discrete or integrated, intercalary or terminal, cylindrical gradually tapering to the apex, straight or curved. Micro-conidia hyaline, oblong with round ends, $(4-) 5-5.5(-7) \times 2(-2.5)$ $\mu \mathrm{m}$ (avg. $5.4 \times 2.1 \mu \mathrm{m}$ ), smooth, in chains, endogenous. Macro-conidia hyaline, oblong with truncate ends, $(5-) 6-7(-9) \times 3-3.5(-4) \mu \mathrm{m}($ avg. $6.5 \times 3.3 \mu \mathrm{m})$, smooth, in chains, endogenous. 


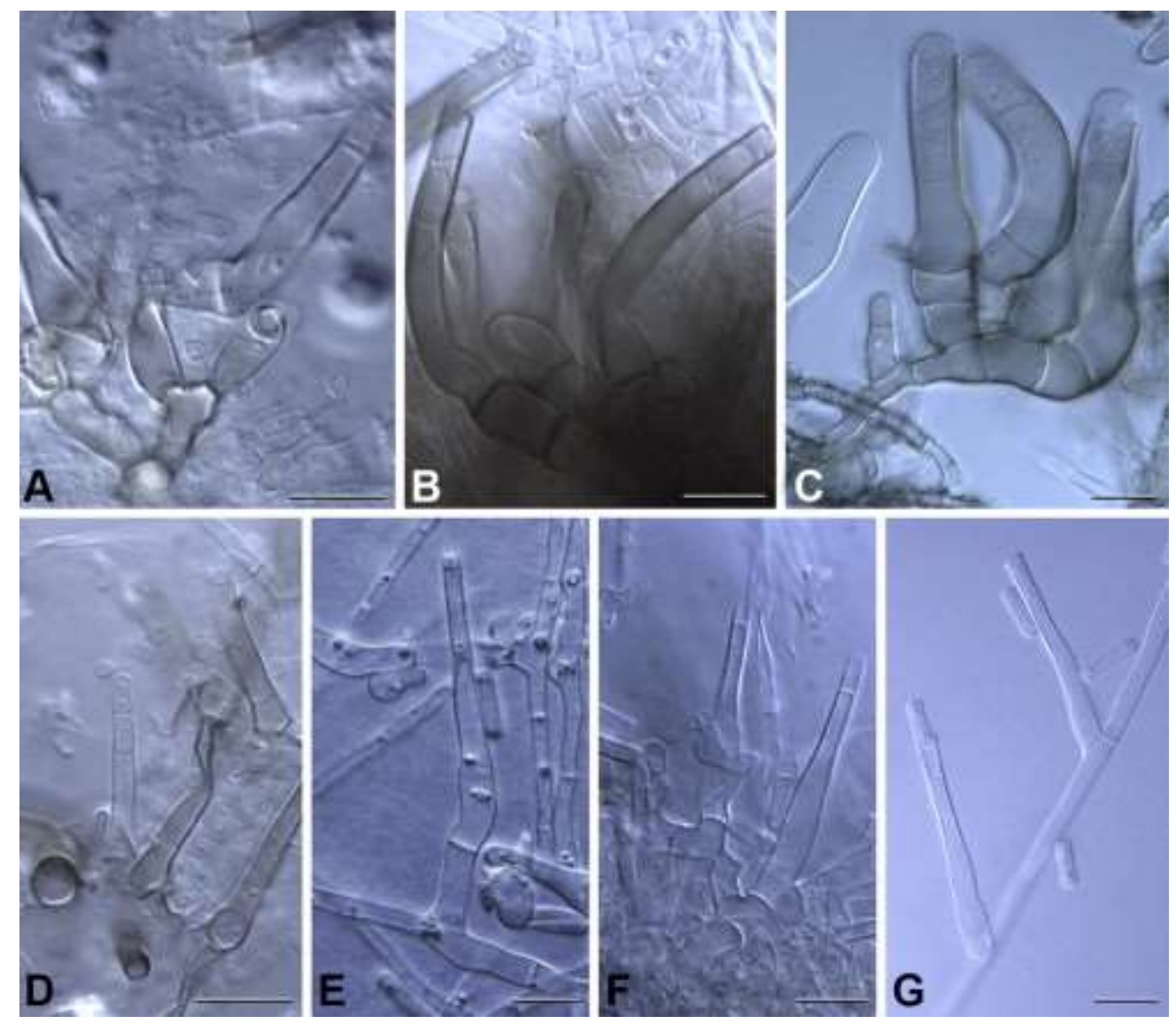

Fig. 6. Photographic images of conidiophores. a, d. Cornuvesica crypta (Herb.IMI 200338). e. Cor. falcata (ATCC 36538). b, f. Cor. acuminata (UAMH 9702). c, g. Cor. magnispora (CBS $134697=$ CMW 37282). a-c.

Conidiophores of macro-conidia. $\mathrm{d}$-g. Conidiophores of micro-conidia. Scale bars: $\mathrm{a}-\mathrm{g}=10 \mu \mathrm{m}$.

Culture characteristics - Colonies showing irregular growth, white near the center, becoming transparent towards the edge, flat, mycelium mostly submerged, not densely compact, showing no effect on medium, becoming fertile in $7 \mathrm{~d}$. There was no growth at 30 ${ }^{\circ} \mathrm{C}$ and $35^{\circ} \mathrm{C}$ and at other temperatures showed extremely slow growth, reaching $7 \mathrm{~mm}$ diam at $15^{\circ} \mathrm{C}$ in $21 \mathrm{~d}, 20 \mathrm{~mm}$ at $20^{\circ} \mathrm{C}$ and $19 \mathrm{~mm}$ at $25^{\circ} \mathrm{C}$. The addition of $300 \mu \mathrm{M} \mathrm{FeCl}{ }_{3}$ to the medium showed no effect on the growth.

Specimens examined: United Kingdom: England, Suffolk, King's Forest, on a slice from cut stump of Betula pendula after 21 d incubation in a damp chamber (N.G. Refs. TL796721), Mar. 1975, A.D.M. Rayner, Herb. IMI 200338, holotype; England, Betula sp., deposited by H.J. Hudson, a dried culture of ATCC 36538, PREM 60965, epitypus hic designatus, exepitype ATCC 36538 = CMW 37652. 
Notes - Cornuvesica crypta was initially reported as Ceratocystis falcata by Rayner and Hudson (1977). We have designated the herbarium specimen they deposited in Herb. IMI as holotype. A culture of the same fungus was deposited by H. J. Hudson to ATCC, with the only information linked to it that it originated from a Betula sp. in England. The possibility exists that this isolate was obtained from the same material as the Herb. IMI specimen. However, in the absence of evidence confirming a link between the specimen and isolate, we consider the two as distinct.

Rayner and Hudson (1977) were able to obtain the asexual form of the fungus from single ascospore cultures on artificial media and described it as a Chalara (Thielaviopsis) state. The conidia of these isolates were 'oblong with truncate ends, 5-8 $\times 1.5-2.0 \mu \mathrm{m}$ ' (Rayner and Hudson 1977). We observed two thielaviopsis-like asexual states on the original herbarium specimen, with distinct ranges of conidial dimensions, with micro-conidia $(4-7 \times 2-2.5 \mu \mathrm{m})$ more abundant (Fig. 7a, b). Rayner and Hudson (1977) might have overlooked the presence of macro-conidia $(4.5-9 \times 2.5-4 \mu \mathrm{m})$ on the specimen due to their scarcity compared to micro-conidia. In the present study, the living culture produced conidia measuring 5-11.5 x 2-3 $\mu \mathrm{m}$ (avg. $8 \times 2.2 \mu \mathrm{m}$ ), resembling the conidia of smaller size, but longer than those found on the specimens and described in original report (Rayner and Hudson 1977). The same isolate was used by Viljoen et al. (2000) to supplement the description of asexual state of the type species, Cor. falcata, when they established the genus Cornuvesica.

Cornuvesica crypta and Cor. falcata are very similar in their sexual states. Discovery of the asexual state of Cor. falcata in the future could provide valuable morphological characteristics to distinguish these two species from each other. We treat Cor. crypta as a species different to Cor. falcata based on the locality from which it was collected and the substrate on which it was found. It is also morphologically distinct from the other species of Cornuvesica described in this study.

Cornuvesica acuminata Marinc., T.A. Duong, Z.W. De Beer, M.J. Wingf., sp. nov. MycoBank 811611; Fig. 5h-k, Fig. 6b, f, Fig. 7g-l.

Etymology - the name refers to the fact that the ascospores taper abruptly towards their ends. 


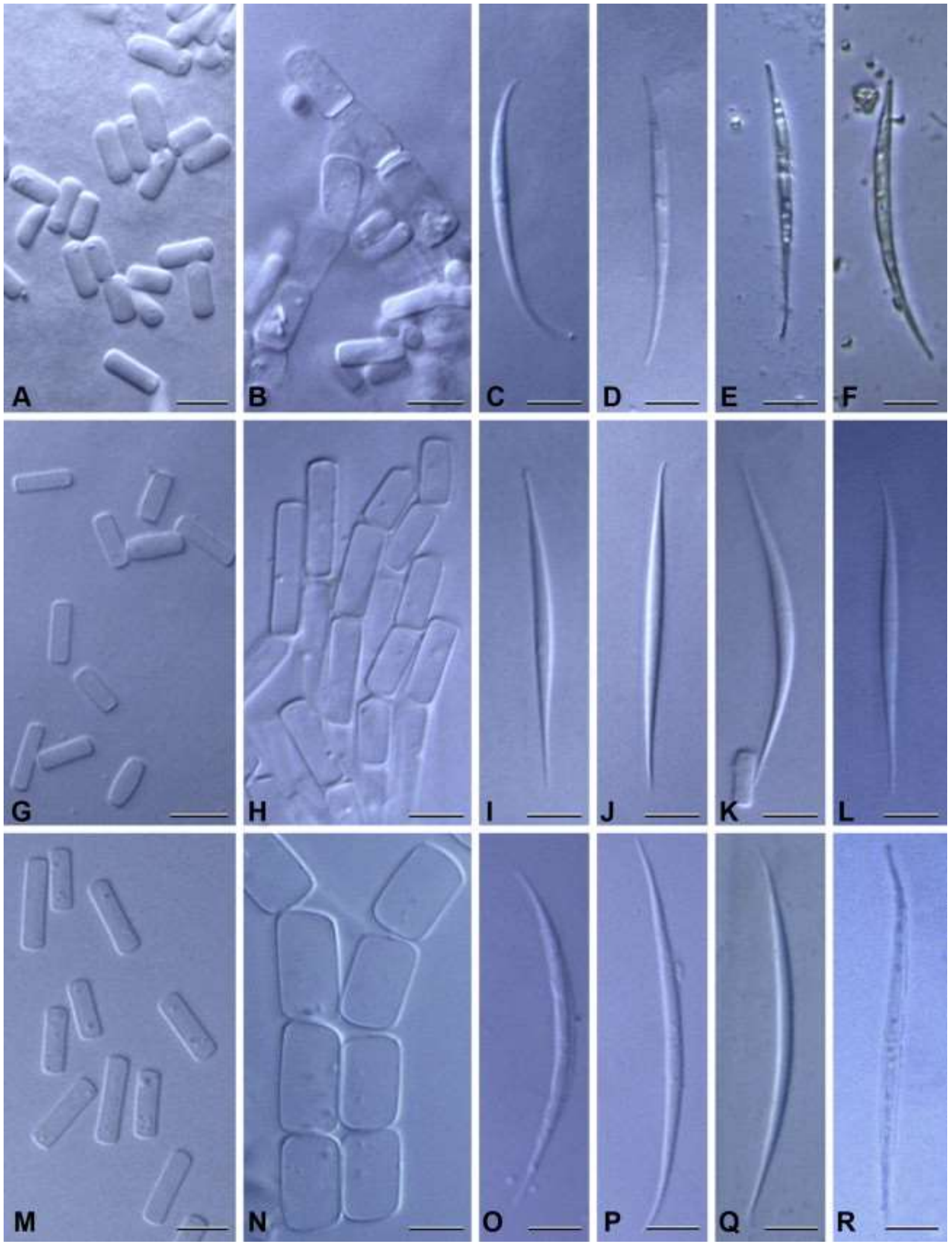

Fig. 7. Photographic images of spores. a-d. Cornuvesica crypta (Herb.IMI 200338). e, f. Cor. falcata (TRTC 33037). g-I. Cor. acuminata. m-r. Cor. magnispora. a, g, m. Micro-conidia. b, h, n. Macro-conidia. c-f, i-l, o-r. Ascospores. Scale bars: $a-r=5 \mu \mathrm{m}$.

On iron-enriched MEA, Ascomata superficial, scattered or some in groups, often embedded in well-developed mycelium on which asexual states are formed, covered with aerial 
hyphae, with a conical opening, dark brown to blackish, 135-160 $\mu \mathrm{m}$ diam. Peridium firm, pseudoparenchymatous, textura epidermoidea to angularis. Ostiolar hyphae convergent, compactly adhered to each other, pale brown to hyaline, 5-14 $\mu \mathrm{m}$ long. Asci evanescent. Ascospores hyaline, falcate, attenuated at the same degree at both ends, sharply attenuating at $1 / 4$ from each end, straight or slightly curved, 1-septate, septum indistinct, supra-median, (21-)27-29(-35.5) × (1-)1.5(-2.5) $\mu \mathrm{m}$ (avg. $27.8 \times 1.6 \mu \mathrm{m})$, thin-walled, smooth, emerging in a tendril. Asexual states thielaviopsis-like with two distinct ranges of conidial dimensions. Micro-conidiophores abundant, micronematous, semi-macronematous, occasionally branched, hyaline, smooth, cylindrical, septated. Macro-conidiophores scarce, macronematous, formed on hyphae originated from perithecium, straight, unbranched or branched, pale brown to brown, smooth, septated. Micro-conidiogenous cells phialidic, collarette indistinct, hyaline, discrete or integrated, intercalary, rarely terminal, cylindrical gradually tapering to the apex, straight or curved, (20-)26-29(-35) $\mu \mathrm{m}$ long, (2-)3(-4) $\mu \mathrm{m}$ wide near the base, (1-)2 $\mu \mathrm{m}$ wide near the apex. Macro-conidiogenous cells phialidic, collarette indistinct, pale brown to brown, discrete or integrated, intercalary or terminal, cylindrical gradually tapering to the apex, straight or curved, (24-)29-32(-37) $\mu \mathrm{m}$ long, (3)5-6.5(-9) $\mu \mathrm{m}$ wide at the base tapering into $(2-) 3-4(-5.5) \mu \mathrm{m}$ at the apex. Micro-conidia hyaline, oblong with truncate to slightly round ends or infrequently one end enlarged, (4)5-6(-9) $\times(1.5-) 2(-2.5) \mu \mathrm{m}$ (avg. $5.5 \times 1.9 \mu \mathrm{m})$, aseptate, smooth, in chains, endogenous. Macro-conidia hyaline, doliiform to rectangular, (5-)7.5-9(-14.5) × (2-)3(-3.5) $\mu \mathrm{m}$ (avg. 8.1 $\times 2.8 \mu \mathrm{m})$, aseptate, smooth, in chains, endogenous.

Culture characteristics - Colonies showing irregular growth, white near the center, becoming transparent towards the edge, flat, mycelium mostly submerged, not densely compact, showing no effect on medium, becoming fertile in $7 \mathrm{~d}$. No growth occurred at 30 ${ }^{\circ} \mathrm{C}$ and $35^{\circ} \mathrm{C}$ and extremely slow growth at other temperatures, reaching $8 \mathrm{~mm}$ diam at 15 ${ }^{\circ} \mathrm{C}$ in $21 \mathrm{~d}, 7 \mathrm{~mm}$ at $20^{\circ} \mathrm{C}$ and $8 \mathrm{~mm}$ at $25^{\circ} \mathrm{C}$. The addition of $\mathrm{FeCl}_{3}$ to the medium showed no effect on the growth.

Specimens examined: New Zealand: North Island, Taupo, Kaingaroa State forest, compartment 5, isolated from beetle galleries in the inner bark or outer sapwood of Pinus radiata, May 1982, J. Reid, PREM 60969, holotype, a dried culture of UAMH 9702, ex- 
holotype UAMH 9702 = CMW 37654; compartment 1212, Pinus radiata, PREM 60970, a dried culture of UAMH 9703, culture UAMH 9703 = CMW 37655; compartment 1212, Larix sp., PREM 60971, a dried culture of UAMH 9701, culture, UAMH 9701 = CMW 37653. Notes - Cornuvesica acuminata was identified as Cop. falcata by Hutchison and Reid (1988) from the North Island of New Zealand, with the first report of Chalara spp. (Thielaviopsis) with two distinct ranges of conidial dimension. In the past, the ex-holotype (UAMH9702) has been included in various phylogenetic analyses erroneously as Cor. falcata (Hausner et al. 1993; Hausner and Reid 2004; Réblovà et al. 2011).

Cornuvesica acuminata can be distinguished from the other species in the genus by its abruptly tapering ascospores and distinct conidial dimensions. Hausner et al. (1993) reported that Cor. acuminata (as Cop. falcata) was insensitive to $0.01 \%$ cycloheximide, displaying a colony growth area reduction of about $30-50 \%$.

Cornuvesica magnispora Marinc., T.A. Duong, Z.W. De Beer, M.J. Wingf., sp. nov. MycoBank 811612; Fig. 5l-o, 6c-g, 7m-r, 8a-i. 


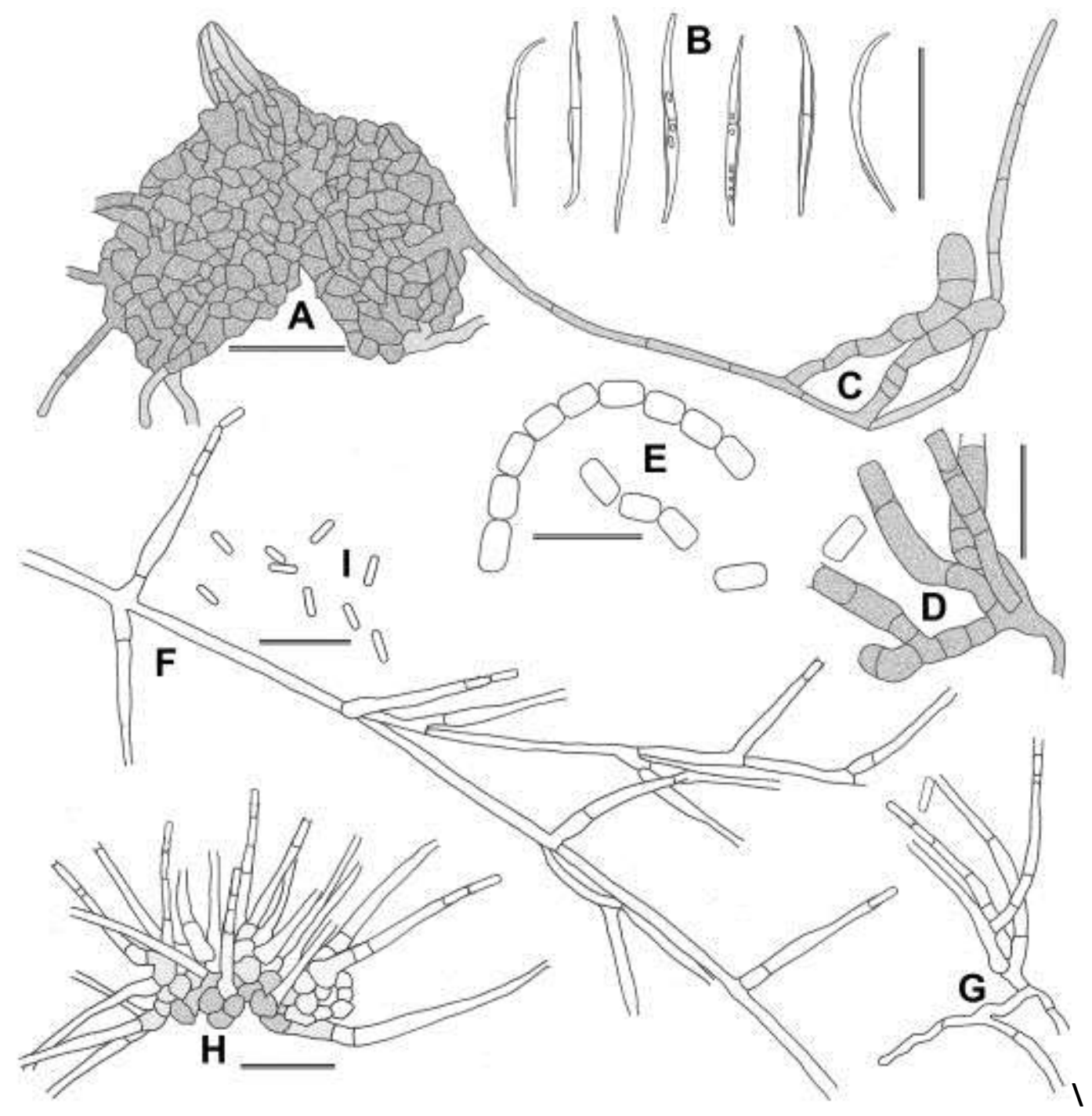

Fig. 8. Drawings of Cornuvesica magnispora. a. A single ascoma with an extended hypha bearing young macroconidiophores (c). b. Ascospores, c. Young macro conidiophores. d. Mature macro-conidiophores. e. Macroconidia. $f$, g. Micro-conidiophores from a fresh isolate. $h$. Microconidiophores from an isolated sub-cultured a few time in the laboratory. i. Micro-conidia. Scale bars: $a-h=25 \mu \mathrm{m}$.

Etymology - name refers to the the larger conidia as compared with other species in the genus.

On iron-enriched MEA, Ascomata superficial, scattered or some in groups, often embedded in well-developed mycelium on which asexual states are also formed, covered with aerial hyphae, with a conical opening, 80-135 $\mu \mathrm{m}$ diam. Peridium firm, pseudoparenchymatous, textura epidermoidea to angularis. Ostiolar hyphae convergent, compactly adhered to each other, pale brown to hyaline, similar to the peridial cells but less pigmented, 5-10 $\mu \mathrm{m}$ high. Asci evanescent. Ascospores hyaline, falcate, gradually attenuated at the same degree at 
both ends, straight or curved, (23.5-)30.5-32(-40) × (1-)1.5(-2) $\mu \mathrm{m}$ (avg. $31.4 \times 1.6 \mu \mathrm{m}), 1-$ septate, septum indistinct, median, thin-walled, smooth. Asexual states thielaviopsis-like with two distinct ranges of conidial dimensions observed. Micro-conidiophores abundant, straight, unbranched or branched, hyaline or rarely pale brown, smooth, 0-2-septated, 5.5$19.5 \times 3-4.5 \mu \mathrm{m}$ (avg. $11.9 \times 3.8 \mu \mathrm{m}$ ). Macro-condiophores less common than those of smaller size, formed on hyphae originated from perithecium, straight, unbranched or branched, pale brown to brown, smooth, 6.5-71.5 × 4.5-10 $\mu \mathrm{m}$ (avg. $32.3 \times 7.6 \mu \mathrm{m}$ ), 0-7septated. Micro-conidiogenous cells phialidic, collarette indistinct, hyaline or occasionally pale brown, discrete or integrated, intercalary or terminal, cylindrical gradually tapering to the apex, 14.5-35.5 $\mu \mathrm{m}$ long, 2-4.5 $\mu \mathrm{m}$ wide at the base, $2-3 \mu \mathrm{m}$ at the apex. Macroconidiogenous cells phialidic, collarette indistinct, pale brown, discrete or integrated, intercalary or terminal, cylindrical gradually tapering to the apex, 23.5-54 $\mu \mathrm{m}$ long, 8-13 $\mu \mathrm{m}$ wide at the base, 5.5-9 $\mu \mathrm{m}$ at the apex. Micro-conidia hyaline, oblong with truncate ends, $(4-) 7-8(-10.5) \times(1.5-) 2(-2.5) \mu \mathrm{m}$ (avg. $7.4 \times 2.0 \mu \mathrm{m})$, aseptate, smooth, in chains, endogenous. Macro-conidia hyaline, doliiform, (7-)10-10.5(-18) × (5-)6(-9.5) $\mu \mathrm{m}$ (avg. 10.1 $\times 5.9 \mu \mathrm{m})$, aseptate, smooth, in chains, endogenous.

Culture characteristics - Colonies on iron-enriched MEA showing circular shape, transparent to umber, with radially striated olivaceous veins, flat, mycelium submerged with aerial hyphae woolly, evenly dispersed, density sparse, showing no effect on medium, becoming fertile in $7 \mathrm{~d}$. The Indonesian isolate (CMW 37282) grew at all temperatures but extremely slowly on MEA, reaching $14 \mathrm{~mm}$ at $15^{\circ} \mathrm{C}$ in $21 \mathrm{~d}, 24 \mathrm{~mm}$ at $20^{\circ} \mathrm{C}$ and $25^{\circ} \mathrm{C}, 43 \mathrm{~mm}$ at $30{ }^{\circ} \mathrm{C}$, $7 \mathrm{~mm}$ at $35^{\circ} \mathrm{C}$. The addition of $\mathrm{FeCl}_{3}$ to the medium showed a positive effect on the growth with the isolates reaching $32 \mathrm{~mm}$ at $20^{\circ} \mathrm{C}$ (1.3 times larger than the control), $66 \mathrm{~mm}$ at $25^{\circ} \mathrm{C}$ (2.7 times larger), $80 \mathrm{~mm}$ at $30^{\circ} \mathrm{C}$ (1.9 times larger), $15 \mathrm{~mm}$ at $35^{\circ} \mathrm{C}$ ( 2 times larger) but no effect at $15^{\circ} \mathrm{C}$. The other two isolates (CMW 37280, CMW 37287) showed a similar growth pattern and effect.

Specimens examined: Indonesia: Kalimantan, isolated from freshly made wounds of Gmelina arborea, Dec. 2010, M.J. Wingfield, PREM 60967, holotype, a dried culture of CBS 134679, culture ex-holotype CBS 134697 = CMW 37282; PREM 60966, a dried culture of CBS 
134698, culture CBS 134698 = CMW 37280; PREM 60968, a dried culture of CBS 134699, culture CBS 134699 = CMW 37287, other cultures CMW 37281, CMW 37283-37286.

Notes - Cornuvesica magnispora can be distinguished from the other species by its conidial dimensions and its larger ascospores. Adding iron supplement to the cultures that had been stored for less than one year enhanced growth at all temperatures. In contrast, there was no effect on the cultures that had been maintained in a collection at $5{ }^{\circ} \mathrm{C}$ for more than two years. Cornuvesica magnispora isolates showed sensitivity to $0.05 \%$ cycoloheximide. Addition of this antibiotic resulted in the colony growth areas being decreased by $72-80 \%$ at $20{ }^{\circ} \mathrm{C}$, by $58-62 \%$ at $25^{\circ} \mathrm{C}$ and by $71-93 \%$ at $30{ }^{\circ} \mathrm{C}$.

\section{DISCUSSION}

Ceratocystiopsis spp. owe their notoriety to the fact that many species occur together with ophiostomatoid fungi (Wingfield et al. 1993), in some cases economically important, and living in association with bark beetles that infest conifers. In this regard, the fungus known as Ceratocystiopsis falcata has frequently been encountered on woody substrates and for many years was assumed to be related to other species of Ceratocystiopsis. Viljoen et al. (2000) showed this not to be true and established Cornuvesica to accommodate what they (and others) believed was a single species. The overall results of this study have shown that previous collections of Cor. falcata represent different species and that these are closely related to fungi in the Ceratocystidaceae and the Gondwanamycetaceae (Microascales). In this regard, they are unrelated to species of Ceratocystiopsis in which Cor. falcata was accommodated for many years. The three new Cornuvesica species described in this study shared the common morphological features with the type species, Cor. falcata. These include minute ascomata of less than $160 \mu \mathrm{m}$ diam, indistinct ostiolar hyphae, 2-celled falcate ascospores with attenuated ends and two distinct thielaviopsis-like asexual states. Variations in the sizes of either ascospores or conidia and the ascospore morphology provide relatively obvious morphological features by which these species can easily be identified.

Results of this study have clearly shown that Cornuvesica is not monotypic, as was assumed for many years (Rayner and Hudson 1977; Hutchison and Reid 1988; Viljoen et al. 2000; De 
Beer et al. 2013). This is perhaps not surprising given the fact that fungi, very similar to the type species, Cor. falcata, have been found in many different parts of the world, and on very different but generally woody substrates. Prior to the ready availability of DNA sequence comparisons, it would not have been possible to recognise the cryptic species that have emerged from this study. We thus also expect that additional species of Cornuvesica will be found in the future.

Prior to the availability of DNA sequence data for phylogenetic inference, the taxonomic position of Cornuvesica in relation to other ophiostomatoid fungi was confused. Early studies based on a partial SSU and LSU rDNA sequences showed that Cornuvesica (as Cop. falcata) was more closely related to Ceratocystis than to Ophiostoma (Hausner et al. 1993). It was also suggested that Cornuvesica shared a common ancestry with other Microascalean taxa (Hausner et al. 1993; Hausner et al. 2000) and that it represented a monophyletic lineage with Knoxdaviesia (= Gondwanamyces) and Ceratocystis s. str., exclusive of Sphaeronaemella (Hausner and Reid 2004). Réblovà et al. (2011) segregated the latter genera into two families, Gondwanamycetaceae and Ceratocystidaceae, in the Microascales. The former family includes Knoxdaviesia and Custingophora, and the latter Cornuvesica, Ceratocystis, and Ambrosiella (Réblovà et al. 2011; De Beer et al. 2013). The phylogenetic analyses of SSU and LSU datasets in the present study showed that Cornuvesica spp., including Cor. acuminata, Cor. crypta and Cor. magnispora, form a discrete clade that represents a unique lineage, separated from the Ceratocystidaceae in the Microascales. This is also strongly supported by the distinct morphology and the unusual biology of Cornuvesica spp. The appropriate placement of this genus at the family level should be explored further in a multigene phylogenetic study, including protein-coding genes, that incorporate species representative of all genera currently included in the Microascales.

The ascomata of Cornuvesica spp. do not have well-defined ostiolar hyphae. In the first description of Cor. falcata (as Ceratocystis falcata), the presence of ostiolar hyphae was not mentioned but the small ascomata were described as terminating in 'slightly projecting, rounded hyaline cells' (Wright and Cain 1961). In the preserved slide representing the holotype, it was possible to recognise these hyaline cells that are easily differentiated from 
the dark cells of the ascomatal neck (Fig. 5b, c). Rayner and Hudson (1977) reported that the ostiolar hyphae of Cor. crypta (as Ceratocystis falcata) were absent. We were, however, able to observe the convergent hyaline cells at the apices of the ascomata in Cor. crypta, which are more prominent than those on the type specimen (Fig. 5f, g). Amongst the three newly recognised species, ostiolar hyphae were most obvious in Cor. acuminata (Fig. 5k).

Macro-conidia were closely associated with the presence of a sexual state in species of Cornuvesica. In Cor. magnispora, we observed that the hyphae on which conidiophores giving rise macro-conidia were formed, originated from the bases of the ascomata (Fig. 8a). Most conidiophores producing macro-conidia were also found close to the bases of the ascomata in Cor. acuminata. Hutchison and Reid (1988) made a similar observation for this fungus, which he treated as Cop. falcata (now Cor. acuminata) stating that, 'the larger phialospores formed only in immediate association with the perithecia'. In the present study, macro-conidia were absent in species such as Cor. crypta in which no ascomata were found.

The survival of Cornuvesica species appears to be dependent on the presence of other fungi growing in their vicinity. Evidence for this fact has emerged from previous studies (Rayner and Hudson 1977; Hutchison and Reid 1988) and it was clear in the present investigation. There is also some evidence to suggest that different fungi provide a growth stimulatory effect in different species of Cornuvesica. For example Rayner and Hudson (1977) showed that Acremonium butryi and Trichoderma spp., as contaminants in culture plates, stimulate the growth and ascomatal production in Ceratocystis falcata (now Cor. crypta). Likewise, Hutchison and Reid (1988) showed that the presence of Gliocladium roseum in the galleries of a bark beetle stimulated the growth and sprulation of Ceratocystis falcata (now Cor. acuminata). Results of the present study added credence to this view where a Ceratocystis sp. in the C. fimbriata complex (De Beer et al. 2014) and an undescribed hypocrealean fungus appeared to contribute to the growth of Cor. magnispora. There was no evidence of mycoparasitism and we speculate that Cornuvesica spp. lack the ability to produce certain extracellular metabolites and have acquired the capacity to derive these from other fungi that grow in association with them. 
Relatively simple experiments testing the effect of filtered culture extracts in this study showed conclusively that filtrates from four test fungi increased the growth of Cor. magnispora dramatically. Here, colony diameters were up to 7 times larger than those of the controls, which lacked the various filtrates. The filtrate of the Fusicoccum sp. tested provided the greatest stimulatory effect and this was the same Fusicoccum sp. that Thanh et al. (2002) used to enhance the growth of a new Debaryomyces sp. Thanh et al. (2002) purified the culture extract of this fungus as well as that of a Gliocladium sp. and showed that the extracellular metabolite promoted the growth of the yeast was a siderophore. Siderophores are low molecular weight compounds produced by microorganisms that have a high level of affinity for ferric iron (Winkelman 2007). It seems reasonable to assume that the stimulatory effect on the growth of Cor. magnispora is similar to that described by Thanh et al. (2002) but additional studies would be needed to confirm this.

Adding an iron supplement to the culture medium showed a similar stimulatory effect on Cor. magnispora to that found when culture fitrates of other fungi were added to the growth media. This suggests that Cor. magnispora is similar to the the dependency on iron that Thanh et al. (2002) showed for Debaryomyces mycophilus. However, a confusing aspect of the present study was that this effect was clear for cultures that had been stored for less than one year but it did not occur in cultures of this fungus that had been in storage for more than two years. Similarly, the effect was not seen for Cor. acuminata or Cor. crypta that were sourced from culture collections and had been stored for long periods of time. Those isolates could simply have lost their vigour due to long-term storage.

During routine isolations from woody substrates, apparently saprobic fungi are commonly encountered that grow very poorly, if at all, on artificial culture media. This could be due to many different factors but the fact that it could be due to a reliance of metabolites produced by other microbes has received little attention. An apparently commensal symbiosis, where growth appears only in the presence of other fungi as has been observed in Cor. magnispora in this study, suggests that many apparently saprobic fungi are not collected because commonly used culture media cannot support their growth. Thus, enrichment of isolation media with fungal culture filtrates could offer interesting opportunities to enhance isolation success. Such symbioses might also, at least partially 
explain the descrepency in numbers of fungi isolated from various substrates and those known to be present as shown in contemporary metagenomic studies (Fierer et al. 2007; Kemler et al. 2013; Cuadros-Orellana et al. 2013).

\section{ACKNOWLEDGEMENTS}

We acknowledge financial support from the DST/NRF Centre of Excellence in Tree Health Biotechnology (CTHB), South Africa. We thank the curators of TRTC and Herb. IMI for providing specimens for this study, and are grateful to Dr. Hugh Glen for help with Latinized species names.

\section{REFERENCES}

Cuadros-Orellana S, Leite LR, Smith A, Medeiros JD, Badotti F, Fonseca PLC, Vaz AMB, Oliveira G, Goés-Neto A. 2013. Assessment of Fungal Diversity in the Environment using Metagenomics: a Decade in Review. Fungal Genomics and Biology 3: 110. doi: 10.4172/2165-8056.1000110

Darriba D, Taboada GL, Doallo R, Posada D. 2012. jModelTest 2: more models, new heuristics and parallel computing. Nature Methods 9(8): 772.

De Beer ZW, Duong TA, Barnes I, Wingfield BD, Wingfield MJ. 2014. Redefining Ceratocystis and allied genera. Studies in Mycology 78: In press. doi: 10.1016/j.simyco.2014.10.001

De Beer ZW, Seifert KA, Wingfield MJ. 2013. The ophiostomatoid fungi: their dual position in the Sordariomycetes. In: Seifert KA, De Beer ZW, Wingfield MJ (eds), The ophiostomatoid fungi: expanding frontiers, CBS Biodiversity Series Vol. 12. CBS-KNAW Fungal Biodiversity Centre, Utrecht, The Netherlands: 119.

Duong TA, De Beer ZW, Wingfield BD, Wingfield MJ. 2012. Phylogeny and taxonomy of species in the Grosmannia serpens complex. Mycologia 104: 715-732.

Fierer N, Breitbart M, Nulton J, Salamon P, Lozupone C, Jones R, Robeson M, Edwards RA, Felts B, Rayhawk S. 2007. Metagenomic and small-subunit rRNA analyses reveal the genetic diversity of bacteria, archaea, fungi, and viruses in soil. Applied and environmental microbiology 73 (21): 7059-7066.

Hausner G, Reid J, Klassen GR. 1993. Ceratocystiopsis: a reappraisal based on molecular criteria. Mycological Research 97: 625-633. 
Hausner G, Reid J, Klassen GR. 2000. On the phylogeny of the members of Ceratocystis s.s. that possess different anamorphic states, with emphasis on the asexual genus Leptographium, based on partial ribosomal sequences. Canadian Journal of Botany 78: 903-916.

Hausner G, Eyjolfsdottir GG, Reid J. 2003. Three new species of Ophiostoma and notes on Cornuvesica falcata. Canadian Journal of Botany 81: 40-48.

Hausner G, Reid J. 2004. The nuclear small subunit ribosomal genes of Sphaeronaemella helvellae, Sphaeronaemella fimicola, Gabarnaudia betae, and Cornuvesica falcata: phylogenetic implications. Canadian Journal of Botany 82: 752-762.

Hutchison LJ, Reid J. 1988. Taxonomy of some potential wood-staining fungi from New Zealand 1. Ophiostomataceae. New Zealand Journal of Botany 26: 63-81.

Jacobs K, Bergdahl DR, Wingfield MJ, Halik S, Seifert KA, Bright DE, Wingfield BD. 2004. Leptographium wingfieldii introduced into North America and found associated with exotic Tomicus piniperda and native bark beetles. Mycological Research 108: 411-418.

Katoh K, Standley DM. 2013. MAFFT multiple sequence alignment software version 7: improvements in performance and usability. Molecular Biology and Evolution 30: 772-780.

Kawchuk LM, Hutchison LJ, Reid J. 1993. Stimulation of growth, sporulation, and potential staining capability in Ceratocystiopsis falcata. European Journal of Forest pathology 23: 178-181.

Kemler M, Garnas J, Wingfield MJ, Gryzenhout M, Pillay K-A, Slippers B. 2013. Ion Torrent PGM as Tool for Fungal Community Analysis: A Case Study of endophytes in Eucalyptus grandis Reveals High Taxonomic Diversity. PLoS ONE 8(12): e81718. doi:10.1371/journal.pone.0081718

Rayner ADM, Hudson HJ. 1977. Ceratocystis falcata and its conidial state. Transactions of British Mycological Society 68: 315-316.

Réblovà M, Gams W, Seifert KA. 2011. Monilochaetes and allied genera of the Glomerellales, and a reconsideration of families in the Microascales. Studies in Mycology 68: 163-191.

Ronquist F, Teslenko M, van der Mark P, Ayres DL, Darling A, Höhna S, Larget B, Liu L, Suchard MA, Huelsenbeck JP. 2012. MrBayes 3.2: efficient Bayesian phylogenetic inference and model choice across a large model space. Systematic Biology 61: 539-542.

Seifert KA, De Beer ZW, Wingfield MJ. 2013. The ophiostomatoid fungi: expanding frontiers. CBS Biodiversity Series 12. CBS-KNAW Biodiversity Centre. Utrecht, the Netherlands. 
Silvestro D, Michalak I. 2012. raxmIGUI: a graphical front-end for RAxML. Organisms Diversity and Evolution 12: 335-337.

Tamura K, Stecher G, Peterson D, Filipski A, Kumar S. 2013. MEGA6: Molecular Evolutionary Genetics Analysis Version 6.0. Molecular Biology and Evolution 30: 2725-2729.

Thanh VN, Van Dyk MS, Wingfield MJ. 2002. Debaryomyces mycophilus sp. nov., a siderophore-dependent yeast isolated from woodlice. FEMS Yeast Research 2: 415-427.

Upadhyay HP. 1981. A monograph of Ceratocystis and Ceratocystiopsis. University of Georgia Press, Athens, Georgia, U.S.A.

Vilgalys R, Hester M, 1990. Rapid genetic identification and mapping of enzymatically amplified ribosomal DNA from several Cryptococcus species. Journal of Bacteriology 172: 4238-4246.

Viljoen CD, Wingfield MJ, Jacobs K, Wingfield BD. 2000. Cornuvesica, a new genus to accommodate Ceratocystiopsis falcata. Mycological Research 104: 365-367.

Wingfield MJ, Seifert KA, Webber J. 1993. Ceratocystis and Ophiostoma: Taxonomy, Ecology and Pathogenicity. APS Press: St. Paul, Minnesota, U.S.A.

Wingfield MJ. 1993. Problems in delineating the genus Ceratocystiopsis. In: Wingfield MJ, Seifert KA, Webber JF (eds), Ceratocystis and Ophiostoma: taxonomy, ecology and pathogenicity. APS Press, St. Paul, Minnesota, U.S.A: $21-26$.

White TJ, Bruns T, Lee S, Taylor J, Innis MA, Gelfand DH, Sninsky JJ, White TJ, 1990. Amplification and direct sequencing of fungal ribosomal RNA genes for phylogenetics. In: Innis MA, Gelfand DH, Sninsky JJ, White TJ (eds), PCR protocols: a guide to methods and applications. Academic Press, New York, U.S.A: 315-322.

Winkelmann G. 2007. Ecology of siderophores with special reference to the fungi. Biometals 20: 379-392.

Wright EF, Cain RF. 1961. New species of the genus Ceratocystis. Canadian Journal of Botany 39: 1215-1230. 